\title{
Metastatic Digestive System Carcinoma
}

National Cancer Institute

\section{Source}

National Cancer Institute. Metastatic Digestive System Carcinoma. NCI Thesaurus. Code C133839.

A carcinoma that arises from the gastrointestinal system and has metastasized to other anatomic sites. 